\title{
Trânsito de bovinos nos estados do Mato Grosso e Mato Grosso do Sul, Brasil
}

\author{
[Movement of cattle in the states of Mato Grosso and Mato Grosso do Sul, Brazil] \\ R.O. Capanema ${ }^{1}$, J.P.A. Haddad ${ }^{2}$, P.L.S. Felipe ${ }^{1}$ \\ ${ }^{1}$ Aluno de pós-graduação - Escola de Veterinária - UFMG - Belo Horizonte, MG \\ ${ }^{2}$ Escola de Veterinária - Universidade Federal de Minas Gerais - Belo Horizonte, MG
}

\begin{abstract}
RESUMO
Compreender a dinâmica de atuação dos frigoríficos contribui para a definição de prioridades e para o estabelecimento de barreiras sanitárias, em caso de uma possível emergência sanitária, ou para a busca de estratégias para a erradicação de enfermidades bovinas. O objetivo deste estudo foi analisar e descrever as áreas de abrangência dos principais municípios que possuem frigoríficos de abate de bovinos com serviço de inspeção federal nos estados do Mato Grosso e Mato Grosso do Sul, revelando as peculiaridades do trânsito bovino. Os dados para execução do estudo, fornecidos pelo Ministério da Agricultura, Pecuária e Abastecimento, foram trabalhados espacialmente e por meio de redes de fluxo. As técnicas de geoprocessamento revelaram as regiões de atuação dos frigoríficos dos principais municípios de destino dos dois estados, no entanto no Mato Grosso a segmentação é mais fácil de ser notada do que no Mato Grosso do Sul. Os resultados sugerem maior regionalização dos polos de abate do Mato Grosso, com regiões de atuação dos frigoríficos bem definidas, e menor comunicação entre os polos de abate. Já no Mato Grosso do Sul, o fluxo, muito intenso, está direcionado para a região central do estado, favorecendo a interação maior entre os municípios.
\end{abstract}

Palavras-chave: movimento de bovinos, geoprocessamento, rede social, vigilância epidemiológica

\begin{abstract}
Understand the operation dynamic among slaughterhouses helps to set up priorities and establish sanitary barriers in event of a possible animal health emergency or the search for strategies of diseases eradication in cattle. The objective of this study was to analyze and describe the acting areas of major cities that have slaughterhouses with federal inspection in the states of Mato Grosso and Mato Grosso do Sul, revealing the peculiarities of animal movement. The data for implementation of the study was provided by the Ministério da Agricultura, Pecuária e Abastecimento, and data was worked up spatially and through social networks. GIS techniques have revealed the regions of operation of the slaughterhouses of the major cities of the states, but in Mato Grosso targeting is easier to notice than in Mato Grosso do Sul. The results suggest a greater regionalization of the slaughter poles of Mato Grosso, with regions where the operation of the slaughterhouses is well defined, and there is less communication between the slaughter poles. In Mato Grosso do Sul there is a very strong flow directed to the central region of the state, encouraging greater interaction between the municipalities.
\end{abstract}

Keywords: GIS, movement of cattle, social network, epidemiologic surveillance

\section{INTRODUÇÃO}

Com a notificação de focos de febre aftosa no Mato Grosso do Sul e Paraná em 2005, as exportações brasileiras de carne bovina sofreram

Recebido em 18 de março de 2011

Aceito em 12 de julho de 2011

E-mail: capanemarenato@yahoo.com.br numerosos embargos. Além disso, o aumento da preocupação dos consumidores internacionais com relação à segurança e à qualidade dos produtos alimentares levou países importadores a restringir cada vez mais o comércio pela imposição de regulamentações sanitárias, o que 
muitas vezes representa barreiras não tarifárias para a carne bovina brasileira. A justificativa para essas barreiras está na própria natureza do produto cujo comércio está sujeito à determinação e imposição de normas técnicas e sanitárias (Braun et al., 2008).

No Brasil, observam-se esforços em alguns setores para mudar esta realidade de controle e erradicação de doenças. Na pecuária, um bom exemplo disso é a queda expressiva do número de casos notificados de febre aftosa no país, ficando a doença confinada em regiões de menor importância até a ausência total de casos (Haddad, 1997).

O movimento de bovinos para os frigoríficos representa uma parcela importante do trânsito total do gado, de modo que o contato direto ou indireto oriundo do envio dos bovinos para abate necessita ser investigado para caracterizar por completo as vias de transmissão de doenças infecciosas entre as populações destes animais (Leon et al., 2006). Um animal infectado, ao ser transportado para outro município, torna-se fonte de infecção na nova localidade e, ainda que permaneça apenas temporariamente, pode desencadear um surto (Coelho et al., 2008).

Mesmo para doenças em que o movimento de animais para abate represente um risco de transmissão direta menor, ainda assim existe a transmissão indireta, como, por exemplo, no caso dos veículos que transportam os animais, que podem ser considerados como uma fonte de infecção em movimento, onde a transmissão pode ocorrer enquanto estes não forem desinfetados (Bigras-Poulin et al., 2007). No caso da febre aftosa, a transmissão por via aérea pode ocorrer por longas distâncias em condições climáticas favoráveis (Gloster et al., 2003).

No Mato Grosso do Sul, historicamente, quando se observa uma movimentação mais intensa de bovinos, animais que vão para engorda e para abate implicam maior possibilidade de circulação de fontes de infecção e, consequentemente, maior risco de surgimento de novos focos (Astudillo et al., 1986).

O objetivo geral deste estudo é caracterizar o trânsito nos estados do Mato Grosso e Mato Grosso do Sul, revelando as áreas de abrangência dos principais municípios que possuem frigoríficos para abate de bovinos com inspeção federal. E, mais especificamente, comparar as áreas de abrangência destes municípios nas regiões onde outros frigoríficos atuam, observando as interfaces e a competição entre eles, revelando a dinâmica do trânsito bovino para os principais polos de abate.

\section{MATERIAL E MÉTODOS}

O presente estudo foi desenvolvido com dados cedidos pelo Ministério da Agricultura, Pecuária e Abastecimento (MAPA), referentes aos estados do Mato Grosso e Mato Grosso do Sul, a partir das Guias de Trânsito Animal (GTAs), emitidas pelos órgãos estaduais de defesa sanitária animal (Brasil 1995, 2006a, 2006b, 2007). Trata-se de um estudo observacional, retrospectivo, ecológico, com enfoque na descrição espacial dos registros do trânsito. O estudo teve como base o ano de 2008, quando mais de oito milhões de bovinos foram abatidos nestes dois estados, sendo 4.123.350 bovinos abatidos no Mato Grosso e 3.885.928 no Mato Grosso do Sul, de modo que os dois estados responderam por mais de $25 \%$ do total de bovinos abatidos no país em 2008.

Os dados fornecidos pelo MAPA referem-se ao trânsito oficial e destinado aos frigoríficos submetidos à Inspeção Federal (SIF), de modo que os municípios identificados como polos de abate, tanto do Mato Grosso como do Mato Grosso do Sul, representam o total de bovinos recebidos com finalidade de abate nos frigoríficos com SIF instalados nestes municípios em 2008. Além disso, outro dado utilizado na seleção dos municípios-polo foi o número de GTAs para abate bovino recebidas em 2008, de modo a certificar que além de receberem o maior número de bovinos dos respectivos estados, os municípios polos de abate também receberam o maior trânsito, pois o fluxo de bovinos foi intenso e distribuído ao longo do ano (o que foi verificado por meio das GTAs) e não concentrado em grandes envios pontuais. Os polos de abate bovino identificados no Mato Grosso do Sul em 2008 foram, portanto, os municípios de Campo Grande, Naviraí, Nova Andradina e Bataguassu, e no Mato Grosso foram Várzea Grande, Tangará da Serra, Barra do Garças e Sinop. 
Para a análise espacial, foi utilizado o programa Mapinfo® Professional 8.5 (Mapinfo, 2006), onde os dados foram convertidos para mapas temáticos sob a plataforma de divisão entre estados e municípios do Instituto Brasileiro de Geografia e Estatística - IBGE. Foi realizado um estudo mais aprofundado para os municípios onde estão localizados os maiores frigoríficos e que concentram o trânsito mais intenso nos estados, chamados de polos de abate.

O método escolhido para agrupar os municípios que aparecem com a mesma coloração nos mapas foi o Natural Break; por meio desse recurso, os municípios são agrupados com base em um algoritmo que utiliza a média de cada intervalo para distribuir os dados de forma mais uniforme entre os grupos. Ele distribui os valores de modo que a média de cada intervalo fica o mais próxima possível de cada um dos valores do grupo. Isso garante que os intervalos sejam bem representados por suas médias e que os valores de trânsito bovino em cada um dos intervalos sejam bastante próximos. De uma maneira mais clara e simples: se dois municípios aparecem com a mesma cor no mapa, pode-se afirmar que o trânsito de bovinos oriundos deles é realmente semelhante. Esta técnica permite evitar um erro que ocorre, por exemplo, ao se considerar semelhantes dois municípios que se encontram nos extremos de um mesmo intervalo, se a divisão dos grupos fosse realizada pura e simplesmente agrupando o mesmo número de municípios por faixa.

A análise das redes de fluxo, ou redes sociais, foi realizada por meio do programa Pajek 1.24 (Pajek, 2009); no entanto, antes foram construídas tabelas matriciais a partir dos dados contidos na base de dados das GTAs, em formato adequado ao Pajek 1.24 , contendo os municípios de origem e destino, a latitude e a longitude deles, referenciando numericamente os municípios e também informando o total de bovinos enviados para abate em 2008. Além disso, foram criadas também partições para todas as tabelas matriciais, de maneira que, quando a rede for executada no Pajek 1.24 , estabeleça-se uma classificação enaltecendo os municípios estratégicos, que funcionam como fornecedores de bovinos com finalidade de abate para vários municípios simultaneamente.

Por meio do programa Stata ${ }^{\circledR} / \mathrm{SE} \quad 10.0$ (StataCorp..., 2007), os dados foram submetidos à estatística descritiva com finalidade espacial, revelando, entre outras coisas, os quartis da distribuição, que foram utilizados para executar transformações na rede de fluxo, permitindo criar redes no Pajek 1.24 removendo o primeiro quartil (municípios com menor trânsito), contendo apenas o trânsito acima da mediana e o trânsito do quartil superior, ou seja, daqueles municípios com maior fluxo de bovinos. Este aprofundamento na análise das redes de fluxo, com transformações considerando os quartis, foi realizado para todos os polos de abate separadamente e também para redes maiores contendo todos os polos simultaneamente, permitindo compreender melhor o funcionamento do trânsito bovino e revelando suas peculiaridades.

\section{RESULTADOS E DISCUSSÃO}

No Mato Grosso do Sul, os municípios de Campo Grande, Naviraí, Nova Andradina e Bataguassu tiveram importância relevante no trânsito de bovinos no ano de 2008. No município de Campo Grande, MS, o trânsito, oriundo da região noroeste do estado no primeiro trimestre de 2008 , foi mais intenso com outros municípios como Coxim, MS, e Porto Murtinho, MS, adquirindo importância ao longo do ano como fornecedores de bovinos para Campo Grande, formando a área de abrangência da capital, que se situa em uma posição estratégica no estado, o que favorece o trânsito proveniente de qualquer região, mas com movimento mais intenso e significativo vindo das regiões norte e noroeste do estado (Fig. 1).

Naviraí, MS, situada ao sul do estado, tem uma área de atuação distinta de Campo Grande, pois os bovinos enviados para esse município são provenientes, em grande parte, de municípios do extremo sul do estado, embora Bela Vista, MS, seja uma exceção, uma vez que se situa $374 \mathrm{~km}$ a noroeste de Naviraí e, ainda assim, foi um dos municípios com grande fluxo de animais em 2008 para Naviraí. A própria capital, Campo Grande, que possui grandes frigoríficos, é uma origem importante de bovinos para Naviraí. Sua área de atuação concentra-se no extremo sul e no sudoeste do estado, atribuído, em parte, à concorrência com os frigoríficos de Nova Andradina, MS, e Bataguassu, MS, que ficam no sudeste do estado (Fig. 2).

Em Nova Andradina, MS, a origem dos bovinos a serem abatidos nos frigoríficos do município é mais uniforme, de modo que a própria cidade é o principal fornecedor, ou seja, os frigoríficos compram muitos animais no próprio município. Isto também foi observado por Baptista e Nunes (2007), que verificaram que o trânsito interno do município - origem e destino no mesmo município - é muito importante e crucial no entendimento da movimentação dos bovinos. 


\section{Capanema et al.}

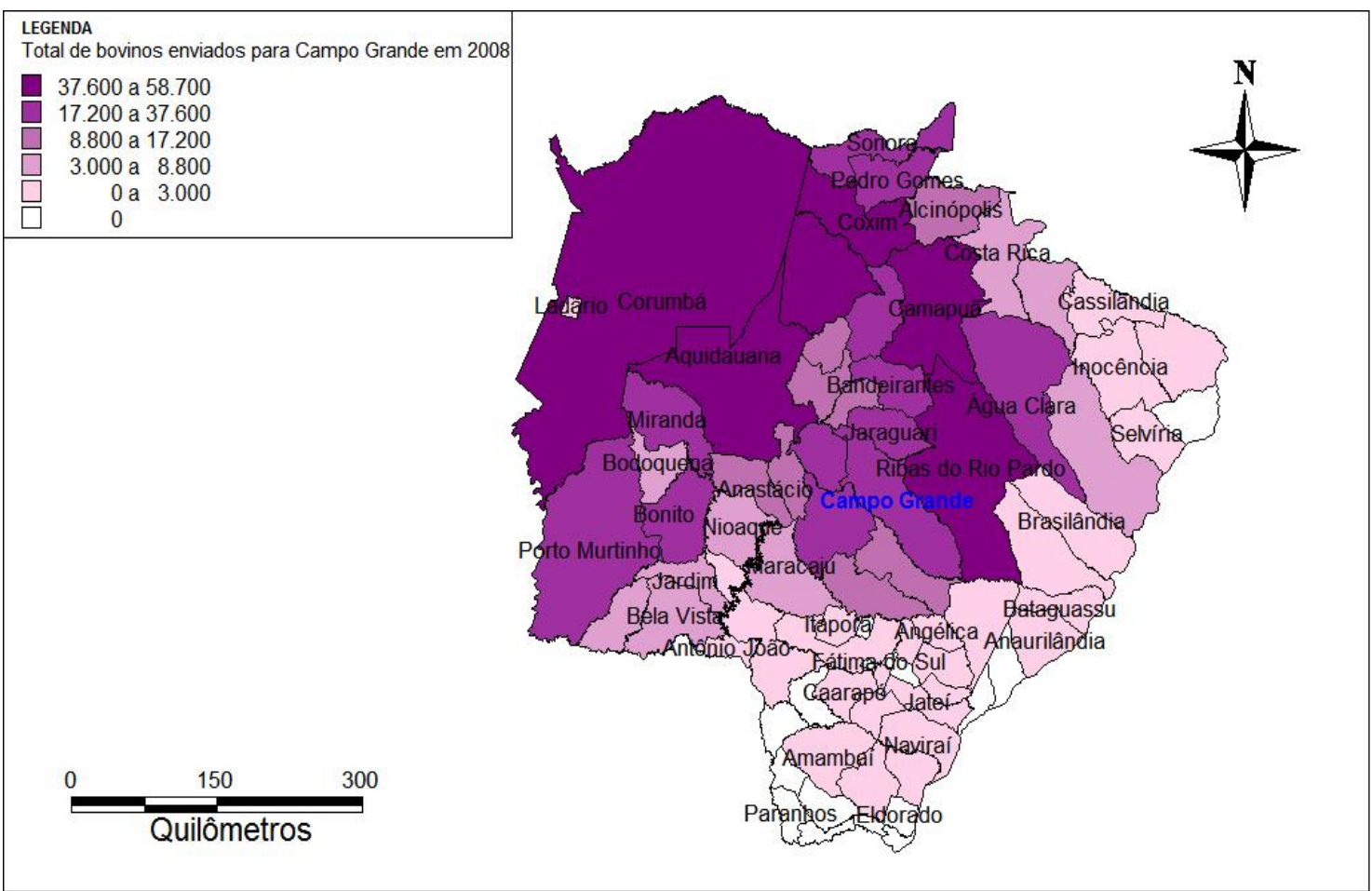

Figura 1. Trânsito de bovinos com finalidade de abate para Campo Grande, MS, em 2008.

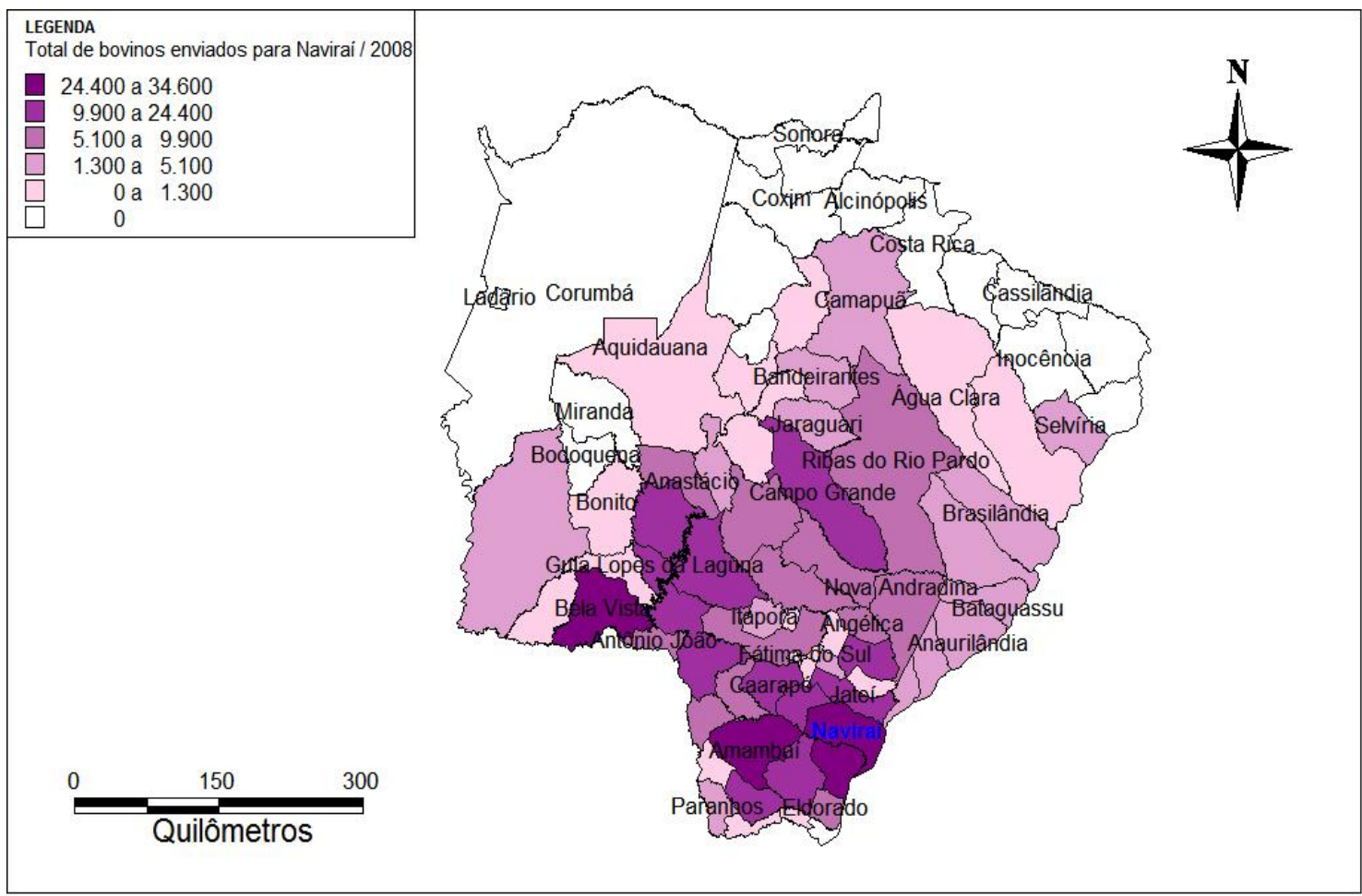

Figura 2. Trânsito de bovinos com finalidade de abate para Naviraí, MS, em 2008. 
O município de Bataguassu, MS, a exemplo de Nova Andradina-MS, também recebe trânsito de bovinos mais uniformemente distribuído, com fornecedores concentrados no entorno do município e em uma região atendida também pelos frigoríficos de Nova Andradina, MS. Os frigoríficos de Campo Grande atenderam às regiões norte e noroeste do estado, os de Naviraí, às do sul e sudeste, e os de Bataguassu e Nova Andradina atuaram principalmente na região compreendida entre o centro e o leste do estado. Leon et al. (2007) também desenvolveram mapas para definir padrões da movimentação de bovinos, nos quais foi possível identificar áreas de risco para ocorrência de febre aftosa.

No Mato Grosso, também foram identificados os municípios de maior relevância no contexto do trânsito de bovinos para abate, levando em conta tanto o número de bovinos enviados para estes polos quanto o número de GTAs emitidas, de modo a certificar que o trânsito realmente é intenso. Portanto, Várzea Grande, MT, Barra do Garças, MT, Tangará da Serra, MT, e Sinop, MT, enquadram-se neste contexto de trânsito intenso de bovinos, de modo que serão analisados juntamente com as regiões a que atendem.

Várzea Grande fica situada ao sul do estado, é adjacente à capital Cuiabá, e tem sua área de abrangência em termos de trânsito de bovinos bastante ampliada, buscando animais inclusive em municípios como Colniza, MT, na divisa com o estado do Amazonas, a 1056km de Várzea Grande. As regiões que apresentam movimento de bovinos por longas distâncias, acima de $1000 \mathrm{~km}$ principalmente, exigem maior atenção para a possibilidade de introdução de doenças, como tuberculose bovina e febre aftosa, em áreas livres (Gilbert et al., 2005).

Barra do Garças tem uma área de atuação bastante distinta de Várzea Grande-MT, uma vez que ocupa praticamente toda a faixa leste do estado, justamente onde os frigoríficos de Várzea Grande têm menor atuação (Fig. 3). Os municípios fornecedores mais importantes de Barra do Garças estão em seu entorno - Nova Xavantina, MT, Água Boa, MT, Araguaiana, MT - e, naturalmente, o próprio município (Fig. 3). Não obstante, o município de São José do Xingu, MT, distante $668 \mathrm{~km}$, é um fornecedor considerável para Barra do Garças, o que mostra que, em algumas situações, os frigoríficos buscam animais a grandes distâncias, prática também observada nos frigoríficos presentes em Várzea Grande, que chegam a buscar bovinos em Colniza, MT, a 1056km. Conforme observaram Mitchell et al. (2005), esse tipo de movimentação, embora menos frequente, possui claramente consequências na biossegurança e no potencial para transmissão de doenças.

Tangará da Serra divide boa parte de sua área de atuação com os frigoríficos de Várzea Grande, dada à relativa proximidade entre estes municípios e à atuação bastante ampliada de Várzea Grande.

Sinop possui frigoríficos que atuam na faixa do centro para o norte do estado, buscando menos bovinos no nordeste (Fig. 4), região mais explorada pelos frigoríficos de Barra do Garças. A região mais importante para Sinop é a norte, com destaque para o município de Juara-MT, distante $291 \mathrm{~km}$, pois este município funcionou como a principal origem de bovinos para abate em 2008, seguida da própria Sinop e de Tabaporã, MT. É perceptível a divisão de atuação dos frigoríficos localizados nos quatro principais municípios de destino - Várzea Grande, Barra do Garças, Tangará da Serra e Sinop -, no entanto, no Mato Grosso essa divisão é mais evidente do que no Mato Grosso do Sul. Conforme afirmaram Coelho et al. (2008), prever quais municípios são fontes para a endemicidade $\mathrm{e}$ entender o caminho da repetição do trânsito animal pode ajudar na concepção de vigilância ideal e estratégias de controle.

No Mato Grosso do Sul, Campo Grande possui trânsito de bovinos proveniente de todas as regiões do estado, a ponto de a minoria dos municípios do Mato Grosso do Sul não ter enviado bovinos para abate em Campo Grande em 2008. Todavia, a rede de fluxo revelou melhor as rotas mais importantes e reconheceu aquelas em que o trânsito se dá somente esporadicamente, pois, conforme afirmou Webb (2005), a prevenção de futuros surtos de febre aftosa e de outras doenças influenciadas pelo trânsito animal requer compreensão das rotas pelas quais as doenças podem se espalhar.

Em Campo Grande, o maior fluxo de bovinos concentra-se em uma região bem delimitada, notadamente distinta das regiões de atuação dos outros municípios-polo do estado, como Naviraí, Nova Andradina e Bataguassu, que também abrigam grandes frigoríficos. As redes de fluxo são importantes no entendimento dos processos epidemiológicos e possuem diversas aplicações, como a restrição de alguns contatos dentro da rede para reduzir a propagação de uma epidemia (Keeling e Eames, 2005). 


\section{Capanema et al.}

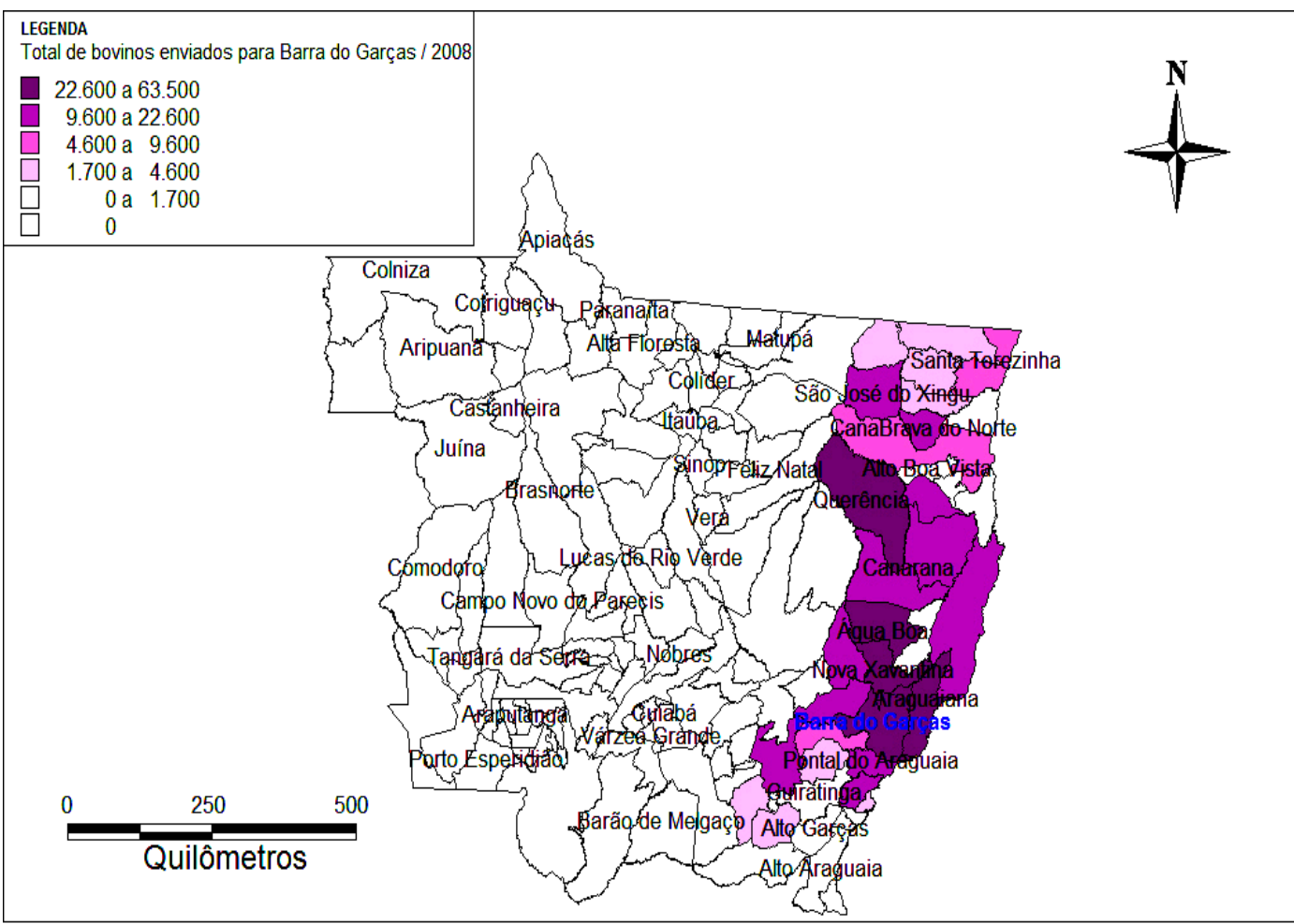

Figura 3. Trânsito de bovinos com finalidade de abate para Barra do Garças, MT, em 2008.

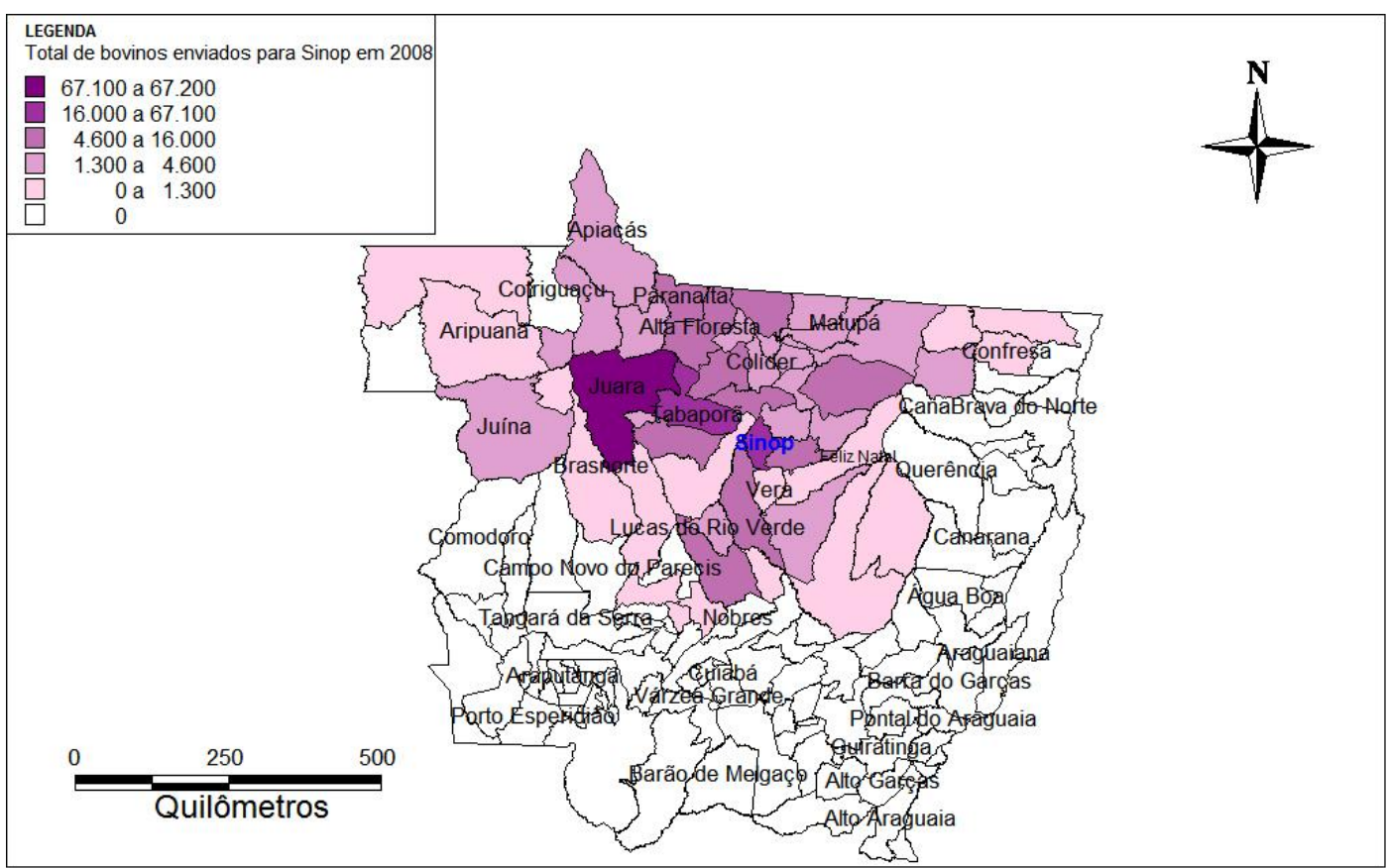

Figura 4. Trânsito de bovinos com finalidade de abate para Sinop-MT, em 2008.

Naviraí, quando se considera o fluxo total de bovinos, independentemente da quantidade, tem fornecedores pulverizados pelo estado, entretanto muitas origens distantes são pouco expressivas, ainda que caracterizem trânsito e não possam ser negligenciadas. Baptista e Nunes (2007) demonstraram que o trânsito é mais propenso de ocorrer entre os municípios vizinhos, embora os 
municípios mais distantes estejam também conectados e, portanto, são importantes no contexto da movimentação animal e, consequentemente, na propagação de doenças.

Os quatro principais polos para abate de bovinos em 2008 no estado do Mato Grosso do Sul Campo Grande, Naviraí, Nova Andradina e Bataguassu - são analisados simultaneamente na Fig. 5. A interpretação é simples e intuitiva, no entanto o significado da cor de cada vértice na figura, com os quatro polos, é explicitado a seguir. A rede com o fluxo completo revela a região de maior importância para o trânsito bovino no estado, representada pelos municípios com vértice vermelho. São municípios com fluxo destinado aos quatro polos de abate. Secundariamente, os municípios com vértice azul escuro revelam uma área de atuação mais ampliada, porém com municípios que enviam para três dos quatro polos. Nas periferias encontram-se os municípios mais distantes dos polos de abate e que têm trânsito mais restrito e direcionado para menos destinos - o vértice verde identifica municípios que enviam para dois polos, o vértice amarelo os municípios que enviam para um polo, o vértice azul claro os municípios que não enviam para nenhum polo. Entretanto, existem municípios nas periferias da rede que são importantes para o polo de abate mais próximo, exercendo, dessa forma, um trânsito mais regionalizado.

Considerando-se apenas o trânsito mais intenso quartil superior -, é possível verificar que o maior fluxo de bovinos se destina aos polos de Campo Grande e Naviraí. Outro dado referente ao fluxo é que a maioria dos municípios de vértice vermelho com envios para os quatro polos - na realidade exerce trânsito intenso somente para um dos polos. Não obstante, o município de Ribas do Rio Pardo, MS, em razão de sua localização estratégica, permanece importante para três polos de abate Campo Grande, Nova Andradina e Bataguassu mesmo em situações de trânsito intenso. OrtizPelaez et al. (2006) verificaram que a informação sobre integrantes que possuem alta centralização em uma rede de contatos pode ser utilizada por sistemas de alerta precoce em países que possuem bancos de dados consistentes para a movimentação animal.

No Mato Grosso, Várzea Grande tem área de atuação bastante pulverizada, com exceção da faixa leste do estado, que é explorada pelos frigoríficos de Barra do Garças. Os frigoríficos de Várzea Grande buscam bovinos por todo o estado, conferindo um trânsito intenso para este município localizado ao lado da capital, Cuiabá.

Na rede de fluxo de Várzea Grande, considerandose somente os municípios do grupo de maior trânsito ( $25 \%$ de maior fluxo), a área de atuação direciona-se ainda mais para oeste, no entanto adiciona uma informação interessante sobre o raio de atuação, que passa a ser de $1000 \mathrm{~km}$, ou seja, bem mais amplo que o habitual, tendo municípios como Rondolândia, MT, Castanheira, MT, Nova Guarita, MT, e Santa Helena, MT, todos mais afastados, entre seus principais fornecedores. A informação sobre a movimentação animal tem aplicação no entendimento dos caminhos que podem ser percorridos pelos patógenos por meio do contato direto ou indireto com os animais e, dessa maneira, é de especial interesse para a vigilância epidemiológica (Bigras-Poulin et al., 2007).

Em Barra do Garças, a análise da rede de fluxo confirmou a predileção dos frigoríficos deste município pela faixa leste do estado, uma vez que é o polo mais próximo dessa região. $\mathrm{O}$ raio de atuação dos frigoríficos de Barra do Garças assemelha-se, na maioria dos casos, aos praticados, por exemplo, no estado do Mato Grosso do Sul, não passando de $450 \mathrm{~km}$ em um cenário de trânsito mais intenso. No entanto, o município de São José do Xingu, MT, é uma exceção, pois está a $668 \mathrm{~km}$ de Barra do Garças, e mesmo considerando-se apenas os municípios com maior fluxo $-25 \%$ de maior trânsito para Barra do Garças -, esse município ainda permanece neste cenário de fluxo intenso de bovinos. Segundo Kiss et al. (2006), o conhecimento sobre o risco de transmissão de uma doença e a estimativa do tamanho final de uma epidemia se aproximam de uma situação real somente se existir um conhecimento prévio da estrutura de contatos que direciona uma epidemia.

Os quatro polos de abate de bovinos no estado do Mato Grosso foram analisados simultaneamente por meio da rede de fluxo (Fig. 6), com resultados distintos da análise realizada para o estado do Mato Grosso do Sul, onde existem concentração e proximidade maior dos polos. No Mato Grosso, os polos de abate comunicam-se menos entre si. Estes padrões do trânsito, especificamente para abate, são importantes epidemiologicamente, uma vez que representam uma parcela muito significativa da movimentação total de bovinos (Bigras-Poulin et al., 2006). 


\section{Capanema et al.}

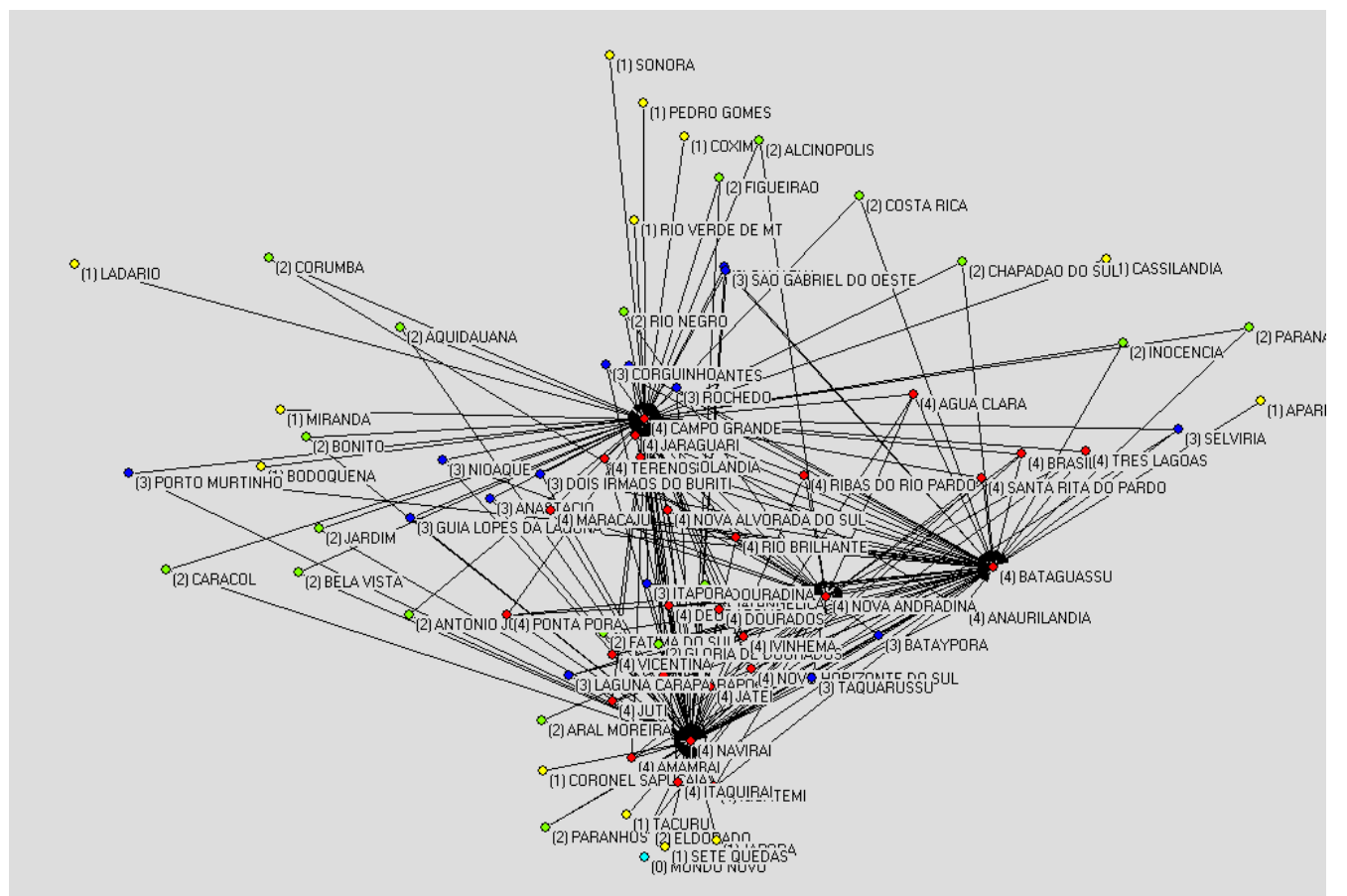

Figura 5. Fluxo de bovinos total para os quatro polos - Campo Grande, MS, Naviraí, MS, Nova Andradina, MS e Bataguassu, MS - em 2008. Municípios que enviaram para quatro polos - vértice vermelho -, para três polos - azul escuro -, para dois polos - verde -, para um polo - amarelo -, e para nenhum polo - azul claro.

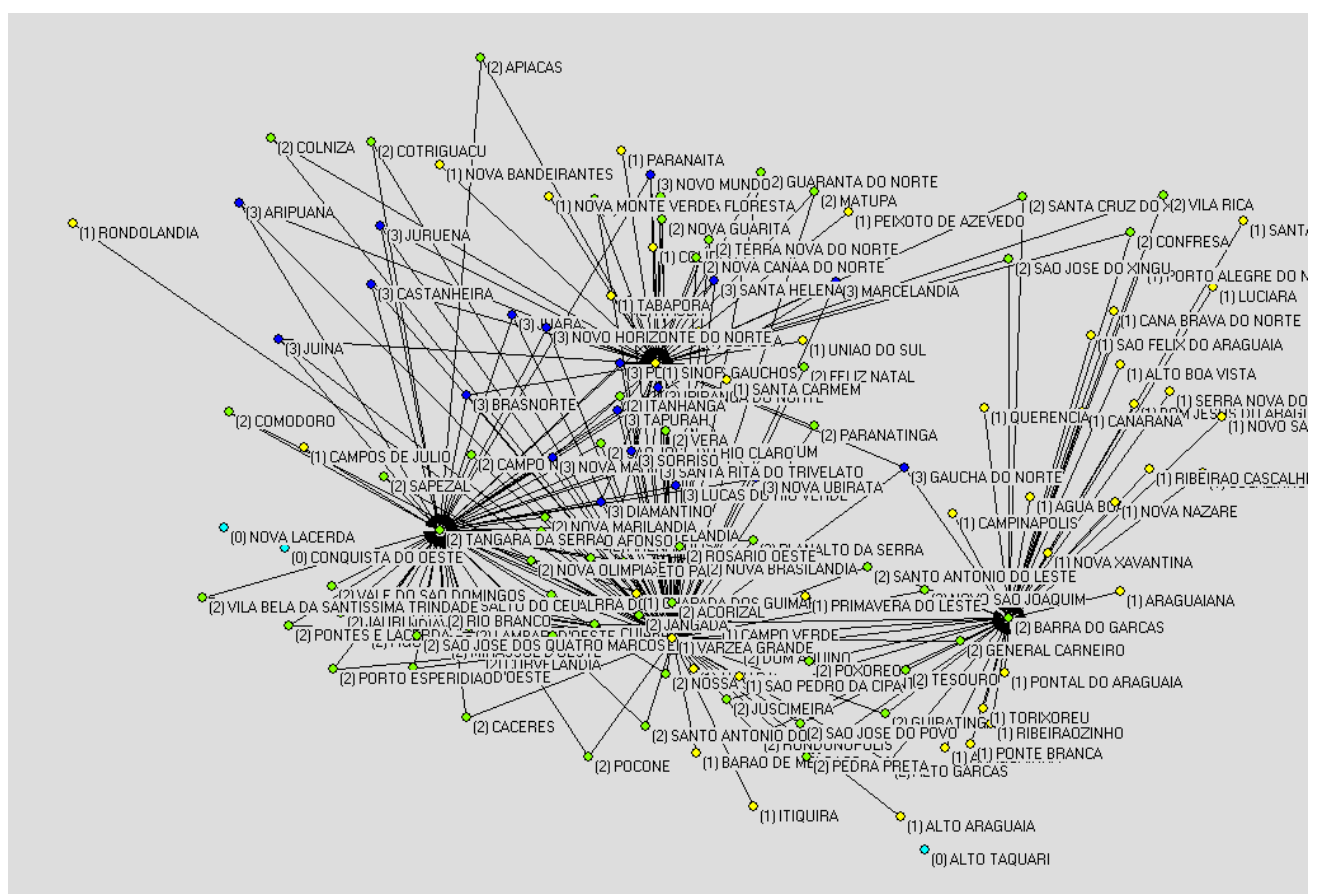

Figura 6. Fluxo de bovinos total para os quatro polos - Várzea Grande, MT, Barra do Garças, MT, Tangará da Serra,MT e Sinop, MT - em 2008. Municípios que enviaram para três polos - vértice azul escuro -, para dois polos - verde -, para um polo - amarelo -, e para nenhum polo - azul claro. 
$\mathrm{Na}$ rede de fluxo para os quatro polos do Mato Grosso, não há nenhum município com envio de animais para todos os polos, ao contrário do Mato Grosso do Sul, que revelou diversos municípios nesta situação. Na rede de fluxo do Mato Grosso, isto ocorre em razão da localização mais deslocada do polo de Barra do Garças em relação aos demais, confirmado pela presença de municípios no centro e no noroeste do estado, que enviam bovinos para os outros três polos, ficando o polo de Barra do Garças isolado na faixa leste do estado.

Considerando-se somente o fluxo mais intenso quartil superior -, a maior independência dos frigoríficos de Barra do Garças é confirmada, assim como o papel mais relevante exercido pelos polos de Várzea Grande, Barra do Garças e Tangará da Serra, ficando o polo de Sinop em posição secundária e mais atuante no norte do estado. É importante que as informações sobre a movimentação de bovinos estejam sempre à disposição, pois, segundo Tomassen et al. (2002), usualmente não se dispõe de muito tempo para levantar dados que orientem a tomada de decisões no caso de surtos como os de febre aftosa.

\section{CONCLUSÕES}

Com base na movimentação encontrada, fica evidente a importância de as autoridades sanitárias terem em mãos estudos que envolvam a análise espacial do trânsito bovino, pois estes permitem identificar os padrões da movimentação, evidenciando diferenças na dinâmica do fluxo de animais. Estas informações também favorecem a prevenção da disseminação de doenças por parte da vigilância epidemiológica, mas estudos continuados são necessários para sugerir estratégias que possam ser aplicadas em todo o país, implicando melhorias nas políticas de monitoramento e na condição sanitária dos rebanhos brasileiros.

\section{AGRADECIMENTOS}

Os autores agradecem ao Ministério da Agricultura, Pecuária e Abastecimento a cessão dos dados para execução deste estudo, e ao Conselho Nacional de Desenvolvimento Científico e Tecnológico, pelo auxílio financeiro para a execução do projeto - processo 479828/2007-5.

\section{REFERÊNCIAS}

ASTUDILLO, V.M.; DORA, J.F.P.; SILVA, A.J.M. Ecosystems and regional strategies for foot-and-mouth disease control. Application to the case of Rio Grande do Sul, Brazil. Bol. Centro Panam. Fiebre Aftosa, v.52, p.63-77, 1986.

BAPTISTA, F.M.; NUNES, T. Spatial analysis of cattle movement patterns in Portugal. Vet. Ital., v.43, p.611-619, 2007.

BIGRAS-POULIN, M.; THOMPSON, R.A.; CHRIEL, M. et al. Network analysis of Danish cattle industry trade patterns as an evaluation of risk potential for disease spread. Prev. Vet. Med., v.76, p.11-39, 2006.

BIGRAS-POULIN, M.; BARFOD, K.; MORTENSEN, S. et al. Relationship of trade patterns of the Danish swine industry animal movements network to potential disease spread. Prev. Vet. Med., v.80, p.143-165, 2007.

BRASIL. Ministério da Agricultura e do Abastecimento. Portaria n. 22, de 13 de Janeiro de 1995. Aprovação (modelo anexo) da Guia de Trânsito Animal (GTA), a ser utilizada em todo o Território Nacional, para o trânsito interestadual de animais, assim como de animais destinados ao abate em matadouros abastecedores de mercados internacionais. Diário Oficial da União, Brasília, 13 de janeiro 1995, Seção 1, p. 761.

BRASIL. Ministério da Agricultura e do Abastecimento. Instrução Normativa n. 18 de 18 de julho de 2006. Aprovação (modelo anexo) da Guia de Trânsito Animal (GTA), a ser utilizada em todo o território nacional para o trânsito de animais vivos, ovos férteis e outros materiais de multiplicação animal. Diário Oficial da União, Brasília, 20 de julho de 2006a, Seção 1, p. 12.

BRASIL. Ministério da Agricultura e do Abastecimento. Instrução Normativa n. 39 de 24 de novembro de 2006. O modelo de GTA aprovado pela Portaria $n^{\circ} 22$, de 13 de janeiro de 1995, terá validade e será aceito paralelamente ao modelo aprovado pela Portaria $n^{\circ} 18$, de 18 de julho de 2006, até 22 de julho de 2007. Diário Oficial da União, Brasília, 27 de novembro de 2006b, Seção 1, p.2.

BRASIL. Ministério da Agricultura e do Abastecimento. Instrução Normativa n. 38 , de 08 de agosto de 2007. O modelo de Guia de Trânsito Animal - GTA aprovado pela Portaria $n^{\circ} 22$, de 13 de janeiro de 1995, terá validade e será aceito paralelamente ao modelo aprovado pela Instrução Normativa $n^{\circ} 18$, de 18 de julho de 2006, até 31 de agosto de 2007. Diário Oficial da União, Brasília, 09 de agosto de 2007, Seção 1, p.26. 
BRAUN, M.B.S.; SANTOS, F.R.; FIGUEIREDO, A.M. et al. Impacto das barreiras sanitárias e fitossanitárias na competitividade das exportações brasileiras e paranaenses de carne bovina. In: CONGRESSO DA SOCIEDADE BRASILEIRA DE ECONOMIA, ADMINISTRAÇÃO E SOCIOLOGIA RURAL, 46., 2008, Rio Branco, AC. Anais... Rio Branco, SOBER, 2008. p.1-21.

COELHO, F.C.; CRUZ, O.G.; CODEÇO, C.T. Epigrass: a tool to study disease spread in complex networks. Source Code Biol. Med., v.3, p.1-10, 2008.

GILBERT, M.; MITCHELL, A.; BOURN, D. et al. Cattle movements and bovine tuberculosis in great Britain. Nature, v.435, p.491-496, 2005.

GLOSTER, J.; CHAMPION, D.B.; RYALL, J.H. et al. Airborne transmission of foot-and-mouth disease virus from Burnside Farm, Heddon-on-the-Wall, Northumberland, during the 2001 epidemic in the United Kingdom. Vet. Rec., v.152, p.525-533, 2003.

HADDAD, J.P.A. Sistema de informações sobre a febre aftosa no estado de Minas Gerais. 1997. 163f. Dissertação (Mestrado em Medicina Veterinária) Escola de Veterinária, Universidade Federal de Minas Gerais, Belo Horizonte.

KEELING, M.J.; EAMES, K.T.D. Networks and epidemic models. J. Royal Soc. Interf., v.2, p.295-307, 2005.

KISS, I.Z.; GREEN, D.M.; KAO, R.R. The effect of contact heterogeneity and multiple routes of transmission on final epidemic size. Math. Biosci., v.203, p.124-136, 2006.

LEON, E.A.; STEVENSON, M.A.; DUFFY, S.J. et al. A description of cattle movements in two departments of Buenos Aires province, Argentina. Prev. Vet. Med., v.76, p.109-120, 2006.

LEON, E.A.; PUENTES, M.I.; LEDESMA, M.C. et $a l$. The use of geographic information systems for foot-and-mouth disease surveillance in Argentina. Vet. Ital., v.43, p.469-475, 2007.

MAPINFO Professional Version 8.5. Programa de mapeamento e análise geográfica. Troy, NY: Pitney Bowes MapInfo and Group 1, 2006.

MITCHELL, A.; BOURN, D.; MAWDSLEY, J. et al. Characteristics of cattle movements in Britain - an analysis of records from the Cattle Tracing System. Anim. Sci., v.80, p.265-273, 2005.

ORTIZ-PELAEZ, A.; PFEIFFER, D.U.; SOARESMAGALHAES, R.J. et al. Use of social network analisys to characterize the pattern of animal movements in the inicial phases of the 2001 foot and mouth disease (FMD) epidemic in the UK. Prev. Vet. Med., v.76, p.40-55, 2006.

PAJEK Version 1.24. Aplicativo para geração e análise de redes de fluxo. Slovenia: Batagelj and Mrvar, 2009.

STATACORP LP Stata/SE 10.0. Análise estatística e gestão de dados. College Station, TX: StataCorp 2007.

TOMASSEN, F.H.M.; KOEIJER, A.; MOURITS, M.C.M. et al. A decision-tree to optimize control measures during the early stage of a foot-and-mouth disease epidemic. Prev. Vet. Med., v.54, p.301-324, 2002

WEBB, C.R. Farm animal networks: unraveling the contact structure of the British sheep population. Prev. Vet. Med., v.68, p.3-17, 2005. 